\title{
Potential for cadaveric organ retrieval in New South Wales
}

John Hunter Hospital, Newcastle, New South Wales, Australia

Adrian D Hibberd, transplant surgeon

Westmead Hospital, Westmead, New South Wales

Ian Y Pearson, intensive care specialist

Jeremy R Chapman, renal physician

Red Cross Blood Transfusion Service, Sydney, New South Wales Cate J McCosker, research assistant

Paula J Mohacsi, transplant coordinator

Moira P McLoughlin, transplant coordinator

Prince Henry Hospital, Little Bay, New South Wales

Graham J Macdonald, renal physician

Royal Prince Alfred Hospital, Camperdown, New South Wales John F Thompson, transplant surgeon

\section{Centre for Clinical} Epidemiology and Biostatistics, Royal Newcastle Hospital, Newcastle, New South Wales

Dianne L O'Connell, senior lecturer

St Vincent's Hospital, Darlinghurst, New South Wales

Phillip M Spratt, cardiothoracic surgeon

Westmead, New South Wales

Jeffrey S Compton, neurosurgeon

St George Hospital, Kogarah, New South Wales

Mark A Brown, renal physician

Correspondence and reprint requests to: Associate Professor A D Hibberd, Newcastle Transplant Unit, John Hunter Hospital, Locked Bag No 1 ,

Newcastle Mail Centre, Newcastle, New South Wales 2310, Australia.

BMF 1992;304:1339-43

Adrian D Hibberd, Ian Y Pearson, Cate J McCosker, Jeremy R Chapman, Graham J Macdonald, John F Thompson, Dianne L O'Connell, Paula J Mohacsi, Moira P McLoughlin, Phillip M Spratt, Jeffrey S Compton, Mark A Brown

Abstract

Objectives - To measure the potential for cadaver organ retrieval in New South Wales and to determine the reasons for potential donors failing to become actual donors.

Design-Prospective audit of all patients dying in five hospitals in New South Wales between 1 December 1989 and 30 November 1990; quality assurance of the data by independent medical specialist and if disagreement by study committee.

Patients -2879 patients $(100 \%$ of all deaths $)$ yielding 364 patients with coma and 181 potential donors.

Outcome measures-Realistic medically suitable potential donor rate, missed potential donor rate, rate of potential donors with permission refused, donor rate, reasons for realistic medically suitable potential donors failing to become actual donors.

Results -2879 deaths yielded 73 medically suitable potential donors, resulting in 19 actual donors, 30 missed potential donors, 19 potential donors with permission refused, and five in whom adequate resuscitation failed. The most common reason for a potential donor failing to become an actual donor was a decision by the senior medical practitioner to withdraw or not to institute ventilatory or haemodynamic support (26/73). The second major obstacle was refusal of permission by the next of kin (17/73). Assuming that the potential donor rate was that implied by the observed donor rate (13/million population/year) the projected missed potential donor rate was $9 / \mathrm{million}$ population/year $(95 \%$ confidence interval 4 to 15 ) and the projected rate of potential donors with permission refused was $13 /$ million population/year $(95 \%$ confidence interval 5 to 22). Assuming that the rate of potential donors in the study hospitals was the same as in the other New South Wales hospitals, the projected donor rate for New South Wales was $18 /$ million population/year (10 to 26); the projected missed potential donor rate was $15 /$ million population/year ( 7 to 23 ); and the projected rate of potential donors with permission refused was $18 /$ million population/year (10 to 27 ).

Conclusions - The donor rate could be increased $70 \%-80 \%$ by overcoming the reluctance of medical practitioners to resuscitate missed potential donors and increased further by gaining permission for organ retrieval from the next of kin.

\section{Introduction}

The supply of donor organs limits the number of organ transplantations carried out. This limitation applies especially to renal transplants, where maintenance dialysis allows the number of prospective recipients to increase faster than the supply of donor organs. In Australia live donors contribute about $7 \cdot 8 \%$ of renal kidneys for transplantation and less than $1 \%$ of livers for transplantation. ${ }^{1}$ The majority of organs therefore comes from cadaveric donors. In the past five years rates of kidney donation from cadavers were $12 \cdot 3 /$ million population/year in Australia and $11.6 /$ million population/year in New
South Wales. ${ }^{1}$ These rates were lower than those in the United Kingdom (14.5/million population/year) ${ }^{2}$ and the United States (16/million population/year).

Demand for transplantation exceeds organ supply in all countries with established transplantation programmes. It has been suggested, however, that supply would be adequate if all potential donors became actual donors. ${ }^{4}$ Few comprehensive studies have measured this difference between potential and actual donor rates. Gore et al studied intensive care units and Gentleman et al audited a neurosurgical unit. ${ }^{256}$ None of these studies considered other areas in the hospital where brain death might occur, such as the coronary care department, primary and emergency care units, or neurology departments. Salih et al surveyed 21 hospitals: the likelihood of a patient becoming a potential donor was not decided by clinicians.' Hence the New South Wales Histocompatibility Committee, which coordinates solid organ transplantation in New South Wales, undertook a study to address three questions: $(a)$ What is the potential for cadaveric organ retrieval in New South Wales? $(b)$ What are the reasons for potential donors failing to become actual donors? (c) Can the actual donor rate be increased by educational intervention among health care providers caring for potential donors? In this paper we answer the first two questions.

\section{Methods}

STUDY DESIGN

The study consisted of a prospective audit of the medical records of all patients who died in five hospitals (study hospitals) in the 12 month period from 1 December 1989 to 30 November 1990 . Permission to carry out the study was obtained from the Department of Health in New South Wales and the ethics committees of the hospitals.

\section{MEASUREMENTS}

A research assistant, in consultation with a nominated medical specialist from each hospital, abstracted and coded data from each medical record on to a data entry form. Data collected included the causes of death, whether a patient was a potential donor, the classification of the potential donor at admission and just before cardiac standstill, the place of death within the hospital, the reasons for failing to become an actual donor or for being medically unsuitable, and the specialty of the medical decision maker. A second specialist, independent of the first, also reviewed the data for all patients identified as potential donors. Thirty three out of 181 patients were discussed in detail (by the full committee) because of disagreement about coding of some data items. Changes were made in the coding of the data in 28 of the 33 patients.

\section{DEFINITIONS OF OUTCOMES}

A potential donor was defined as a patient with acute irreversible brain damage that resulted in potential brain death or actual brain death. Potentially brain dead patients were apparently or imminently brain 
dead before cardiac standstill. They were classified into five groups depending on their ventilatory and haemodynamic management before cardiac standstill (groups $0-4$, table I). Actually brain dead patients had brain death diagnosed by formal protocol. ${ }^{8}$ They were classified into an additional two groups depending on their haemodynamic management (groups 5-6, table I).

$A$ realistic potential donor was defined as a potential donor for whom ventilatory or haemodynamic support, or both, was considered appropriate for the patient's welfare and who was considered medically suitable for organ retrieval.

An unrealistic potential donor was defined as a potential donor for whom ventilatory or haemodynamic support, or both, was considered not to be primarily for the patient's benefit or as a potential donor who remained in a stable vegetative state after withdrawal of ventilatory support.

A missed potential donor was defined as a realistic medically suitable potential donor who failed to become an actual donor because of lack of medical intervention.

A potential donor with permission refused was defined as a realistic medically suitable potential donor in whom permission for retrieval was refused by relative, patient, or coroner.

An actual donor was defined as a patient with actual brain death in whom organ retrieval occurred.

\section{STATISTICAL METHODS}

All data were initially entered on to a relational database and then analysed with the SAS statistical package. Actual donors were compared with potential donors with permission refused or with missed potential donors for categorical variables (cause of brain damage, place of death, classification at admission and before cardiac standstill) by the $\chi^{2}$ test or Fisher's exact test. ${ }^{9}$ The pairs of donor groups were compared on age and time of death with the Wilcoxon two sample test because the data were highly skewed.

Two methods were used to estimate the possible donor rate in New South Wales. The assumption underlying the first method was that the rate of realistic medicallÿsuitable potential donors for all of New South Wales was the same as in the study hospitals, but differences in the distribution of the causes of death between the study hospitals and New South Wales hospitals were allowed for. It was also necessary to assume that the conversion rate of realistic medically suitable potential donors to actual or other types of donors was the same in the study hospitals and in New South Wales hospitals within the causes of death. The potential or actual donors in the study hospitals were stratified according to the cause of death. The number of donors for each cause was divided by the number of deaths from that cause occurring in the study hospitals in the study period and then multiplied by the number of deaths from that cause occurring in New South
Wales hospitals for a similar 12 month period ( 1 July 1989 to 30 June 1990). This period was used because it was the latest 12 month period for which complete death data were available. The numbers of potential or actual donors for each cause of death were added to give the projected number for New South Wales. Data about the causes of death in New South Wales hospitals were obtained from the inpatients statistics collection and supplied by the Hunter Health Statistics Unit, University of Newcastle, New South Wales.

The second method allowed for the possibility that the realistic medically suitable potential donor rate for New South Wales was different from that observed in the study hospitals but assumed that the conversion rate of realistic medically suitable potential donors to actual donors was the same in the study hospitals and in New South Wales hospitals. The number or realistic medically suitable potential donors for New South Wales was calculated by dividing the observed number of actual donors in New South Wales for the study period by the proportion of realistic medically suitable potential donors in the study hospitals who became actual donors. The rates of missed potential donors, donors with failed resuscitation, and donors with permission refused were calculated using the same proportions as observed in the study hospitals.

\section{Results}

STUDY GROUP

In 1990 New South Wales had a population of 6112358 served by 78 hospitals including 12 university teaching hospitals and 45 district hospitals. In the five study hospitals there was a total of 2879 deaths in the study period. These deaths represent $25 \%$ of deaths in the Sydney metropolitan hospitals and $15 \%$ of deaths in New South Wales hospitals for a similar 12 month period. All university teaching hospitals and 32 district hospitals had intensive care units. All other district hospitals and the remaining hospitals had ready access to intensive care units by helicopter.

\section{NUMBERS OF POTENTIAL DONORS}

Of 2879 deaths, 2515 were excluded because they were dead on arrival (103), could not be resuscitated (478), were aged over 70 years (646), had never been comatose (810), were neonatal deaths (67), or had cancer (411). Thus there were 364 patients with coma, among whom there were 181 potential donors. Table II shows the numbers of potential donors from each study hospital. Among the unrealistic potential donors 41 remained in a stable vegetative state, and for 36 it was considered that resuscitation would have been solely for the purpose of organ retrieval. Twenty seven patients were medically unsuitable for organ retrieval, and four potential donors with debatable medical suitability were excluded from further consideration

TABLE I-Classification of potential donors

\begin{tabular}{|c|c|c|}
\hline Group & Clinical state & Comment \\
\hline 0 & Not supportable haemodynamically & $\begin{array}{l}\text { Vigorous resuscitation (including ventilation) was done to no avail; adequate organ } \\
\text { perfusion was never established }\end{array}$ \\
\hline 1 & $\begin{array}{l}\text { Not ventilated } \\
\text { Not supported haemodynamically } \\
\text { Brain stem reflexes present }\end{array}$ & $\begin{array}{l}\text { No effort was made to ventilate and support, or support was withdrawn from a patient in a } \\
\text { stable neurological state after satisfactory response to resuscitation; cardiac standstill } \\
\text { resulted }\end{array}$ \\
\hline 2 & $\begin{array}{l}\text { Not ventilated } \\
\text { Not supported haemodynamically } \\
\text { Brain stem reflexes absent }\end{array}$ & $\begin{array}{l}\text { Such a patient was being ventilated when reflexes were found to be absent; support was } \\
\text { withdrawn without formal confirmation of brain death }\end{array}$ \\
\hline 3 & Ventilated but not supported haemodynamically & Ventilation was adequate but haemodynamic support was inadequate or not given \\
\hline 4 & $\begin{array}{l}\text { Ventilated with adequate haemodynamic } \\
\text { support and initial response to resuscitation }\end{array}$ & Full support was provided but cardiorespiratory collapse led to cardiac arrest \\
\hline 5 & $\begin{array}{l}\text { Confirmed brain dead - ventilated but not } \\
\text { supported haemodynamically, with cardiac } \\
\text { arrest as a result }\end{array}$ & $\begin{array}{l}\text { Because the blood pressure was not supported either during or after confirmation of brain } \\
\text { death, cardiac arrest occurred }\end{array}$ \\
\hline 6 & $\begin{array}{l}\text { Confirmed brain dead - ventilated and } \\
\text { supported haemodynamically }\end{array}$ & $\begin{array}{l}\text { Several outcomes were possible: adequate resuscitation failed; permission for organ } \\
\text { retrieval from next of kin was not sought; permission from next of kin was refused; or } \\
\text { actual retrieval occurred }\end{array}$ \\
\hline
\end{tabular}




\begin{tabular}{|c|c|c|c|c|c|c|c|c|c|c|c|}
\hline \multirow[b]{2}{*}{ Hospital` } & \multirow[b]{2}{*}{$\begin{array}{l}\text { No of } \\
\text { deaths }\end{array}$} & \multicolumn{6}{|c|}{ No of potential donors } & \multirow[b]{2}{*}{$\begin{array}{l}\text { No of } \\
\text { actual } \\
\text { donors }\end{array}$} & \multicolumn{3}{|c|}{ Donor rates } \\
\hline & & $\begin{array}{c}\text { Potential } \\
\text { donors }\end{array}$ & $\begin{array}{c}\text { Realistic } \\
\text { potential } \\
\text { donors }\end{array}$ & $\begin{array}{l}\text { Unrealistic } \\
\text { potential } \\
\text { donors }\end{array}$ & $\begin{array}{c}\text { Realistic } \\
\text { medically } \\
\text { suitable potential } \\
\text { donors }\end{array}$ & $\begin{array}{c}\text { Realistic } \\
\text { debatably } \\
\text { medically suitable } \\
\text { potential donors }\end{array}$ & $\begin{array}{c}\text { Realistic } \\
\text { not medically } \\
\text { suitable } \\
\text { potential donors }\end{array}$ & & $\begin{array}{c}\text { Realistic } \\
\text { medically suitable } \\
\text { potential donor } \\
\text { ratef }\end{array}$ & $\begin{array}{c}\text { Actual } \\
\text { donor } \\
\text { rate } \neq\end{array}$ & $\begin{array}{c}\text { Rate of conversion of } \\
\text { realistic medically suitable } \\
\text { potential donors to actual } \\
\text { donors }(\%) \S\end{array}$ \\
\hline 1 & 519 & 33 & 19 & 14 & 16 & 0 & 3 & 3 & $3 \cdot 1$ & $0 \cdot 6$ & 19 \\
\hline 2 & 265 & 15 & 11 & 4 & 9 & 0 & 2 & 4 & 3.4 & $1 \cdot 5$ & 44 \\
\hline 3 & 600 & 21 & 12 & 9 & 8 & 1 & 3 & 1 & $1 \cdot 3$ & $0 \cdot 2$ & 13 \\
\hline 4 & 866 & 77 & 45 & 32 & 31 & 1 & 13 & 9 & $3 \cdot 6$ & 1.0 & 29 \\
\hline 5 & 629 & 35 & 17 & 18 & 9 & 2 & 6 & 2 & $1 \cdot 4$ & $0 \cdot 3$ & 22 \\
\hline Total & 2879 & 181 & 104 & 77 & 73 & 4 & 27 & 19 & & & \\
\hline Mean & & & & & & & & & 2.5 & 0.7 & 26 \\
\hline
\end{tabular}

^All were university teaching hospitals.

TABLE III -Causes of debatable or non-medical suitability of potential donors in study hospitals

\begin{tabular}{|c|c|c|}
\hline Cause & $\begin{array}{c}\text { Medically } \\
\text { unsuitable } \\
\text { potential } \\
\text { donors } \\
(\mathrm{n}=27)\end{array}$ & $\begin{array}{c}\text { Debatably } \\
\text { medically } \\
\text { suitable } \\
\text { potential } \\
\text { donors } \\
(n=4)\end{array}$ \\
\hline Prolonged ischaemia & & 1 \\
\hline Malignant hypertension & & 1 \\
\hline Cancer suspected & 1 & 1 \\
\hline Acute renal impairment & 3 & 1 \\
\hline Major sepsis & 7 & \\
\hline Intravenous drug misuse & 3 & \\
\hline HIV confirmed or suspected & 2 & \\
\hline Hepatitis B & 2 & \\
\hline Chronic renal failure & 2 & \\
\hline Multiple organ failure & 2 & \\
\hline Pelvic injuries plus anuria & 1 & \\
\hline Multiple trauma plus retroperitoneal bleed & 1 & \\
\hline Undiagnosed intra-abdominal pathology & 1 & \\
\hline Acute renal failure plus rhabdomyolysis & 1 & \\
\hline Idiopathic aplastic anaemia & 1 & \\
\hline
\end{tabular}

(table III). Hence there were 73 realistic medically suitable potential donors (table II).

\section{POTENTIAL DONOR RATES BY HOSPITAL}

Table II shows the potential donor rates for the study hospitals and the rates of converting realistic medically suitable potential donors to actual donors. This potential donor rate was not related to the rate of conversion. Differences in the distribution of the cause of death by hospital did not account for differences in the potential donor rate: in hospitals with high potential donor rates ( $>3 / 100$ deaths) $13.5 \%$ of deaths were due to trauma or cerebral haemorrhage as compared with $12 \cdot 3 \%$ of these deaths in hospitals with low potential donor rates $(<1 \cdot 5 / 100$ deaths) (difference $1 \cdot 2 \%, 95 \%$ confidence interval $-1 \cdot 3 \%$ to $3 \cdot 7 \% ; p>0 \cdot 05)$. Cause of acute brain damage in potential donors (head injury or cerebral haemorrhage), however, neared significance in hospitals with high and low potential donor rates $(5 \cdot 1 \%$ v $3 \cdot 6 \%$, difference $1.5 \%, 0.01 \%$ to $3.0 \%$; $\mathrm{p}=0.05)$. Age at death was significantly different in hospitals with high and low donor rates (median age $67 v 73$ years; $\mathrm{p}<0.0001$ ).

\section{OUTCOMES IN REALISTIC MEDICALLY SUITABLE} POTENTIAL DONORS

The outcomes for these potential donors are shown in Table IV. In the 73 realistic medically suitable potential donors there were 19 actual donors and 54 who failed to become actual donors because resuscitation had not been started or maintained (26), permission had not been sought (3), junior medical staff had not been aware of the possibility of organ retrieval (1), resuscitation failed (5), or permission was refused by next of kin (17), coroner (1), or patient (1). Thus, in the first three categories, there were 30 missed potential donors. Permission was sought in 38 potential donors and refused in $19(50 \%)$.

\section{CHARACTERISTICS OF OTHER POTENTIAL DONORS}

Missed potential donors, when compared with actual donors, were older and less likely to die in intensive care units (table V). They also died of traumatic head

TABLE $\mathrm{V}-$ Missed potential donors compared with actual donors

\begin{tabular}{|c|c|c|c|}
\hline & $\begin{array}{c}\text { No }(\%) \text { of } \\
\text { missed } \\
\text { donors } \\
(\mathrm{n}=30)\end{array}$ & $\begin{array}{c}\text { No }(\%) \text { of } \\
\text { actual } \\
\text { donors } \\
(\mathbf{n}=19)\end{array}$ & $\mathrm{p}$ Value \\
\hline \multicolumn{4}{|l|}{ Cause of brain damage: } \\
\hline Traumatic head injury & $6(20)$ & $9(47)$ & $0 \cdot 06^{\star} \dagger$ \\
\hline Intracranial bleed or thrombosis & $17(57)$ & $9(47)$ & $0 \cdot 57^{\star}+$ \\
\hline Other & $7(23)$ & 1 (5) & \\
\hline \multicolumn{4}{|l|}{ Place of death: } \\
\hline Intensive care unit & $21(70)$ & $19(100)$ & $0.008^{\star}$ \\
\hline \multicolumn{4}{|l|}{ Classification at admission: $\star \star$} \\
\hline $1 \neq$ & $8(27)$ & $3(16)\}$ & \\
\hline 2 or $3 \ddagger$ & $3(10)$ & $2(11)\}$ & 0.04 \\
\hline 4 & $7(23)$ & $11(58)$ & \\
\hline $7 \pi$ & $12(40)$ & $3(16)$ & \\
\hline \multicolumn{4}{|l|}{ 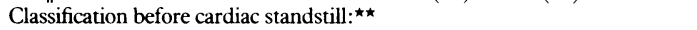 } \\
\hline $1,2,3$, or 4 & $\begin{array}{r}17(57) \\
9(30)\end{array}$ & & $<0.001 \|$ \\
\hline $\begin{array}{l}5 \\
6\end{array}$ & $\begin{array}{l}9(30) \\
4(13)\end{array}$ & $19(100)$ & \\
\hline Median age (years) & 57 & 29 & 0.0007 \\
\hline Median time to death (hours) & 23.5 & 40 & $0 \cdot 159$ \\
\hline
\end{tabular}

^Fisher's exact test.

†Traumatic head injury (yes/no), intracranial bleed or thrombosis (yes/no). $\ddagger$ Groups $1-3$ were combined for $\chi^{2}$ test due to small numbers. SWilcoxon two sample test.

$\chi^{2}$ test.

INeither potentially nor actually brain dead at admission

$\star \star$ See methods section for definitions of outcomes.

TABLE IV-Outcomes in realistic medically suitable potential donors in study hospitals

\begin{tabular}{|c|c|c|c|c|c|c|c|c|c|}
\hline \multirow[b]{2}{*}{ Hospital } & \multirow{2}{*}{$\begin{array}{l}\text { No of } \\
\text { actual } \\
\text { donors }\end{array}$} & \multicolumn{3}{|c|}{ Permission refused by: } & \multirow{2}{*}{$\begin{array}{c}\text { Failed } \\
\text { resuscitation }\end{array}$} & \multirow{2}{*}{$\begin{array}{l}\text { Failure to institute } \\
\text { or withdrawal of } \\
\text { resuscitation }\end{array}$} & \multirow{2}{*}{$\begin{array}{c}\text { Permission not } \\
\text { sought in actually } \\
\text { brain dead patients }\end{array}$} & \multirow{2}{*}{$\begin{array}{c}\text { Lack of } \\
\text { awareness }\end{array}$} & \multirow{2}{*}{$\begin{array}{c}\text { Realistic medically } \\
\text { suitable } \\
\text { potential donors }\end{array}$} \\
\hline & & Next of kin & Coroner & Patient & & & & & \\
\hline 1 & 3 & 3 & & $1^{\star}$ & 1 & 7 & & 1 & 16 \\
\hline 2 & 4 & 3 & & & 1 & 1 & & & 9 \\
\hline 3 & 1 & 2 & 1 & & 1 & 2 & 1 & & 8 \\
\hline 4 & 9 & 8 & & & 2 & 11 & 1 & & 31 \\
\hline 5 & 2 & 1 & & & & 5 & 1 & & 9 \\
\hline \multirow{2}{*}{$\begin{array}{l}\text { Total asked for } \\
\text { permission }(n=38) \\
\text { Total not asked for } \\
\text { permission }(n=35)\end{array}$} & $19 \dagger$ & $17 \dagger$ & $1 t$ & $1 \dagger$ & & & & & \\
\hline & & & & & 5 & 26 & $3 \dagger$ & 1 & 73 \\
\hline
\end{tabular}

$\star$ Patient decided before death not to allow organ retrieval.

†4 Brain dead patients. 
injury less commonly than actual donors $(p=0 \cdot 06)$. Potential donors who did not present with brain death but became brain dead during hospitalisation were likely to be missed. The clinicians responsible for missed potential donors were neurosurgeons (15), intensive care specialists (8), registrars (3), neurologists (2), a nephrologist, and a general physician.

Potential donors with permission refused, compared with actual donors, did not differ significantly in the cause of brain damage, the classification at admission, the time taken to die after admission, or age. Because of small numbers in each group there may be insufficient power to detect clinically important differences.

\section{RETRIEVAL OF AVAILABLE ORGANS}

The organ specific availability rates for actual donors were: kidney pair 19/19 (100\%), cornea pair 18/19 $(95 \%)$, liver $13 / 19(68 \%)$, heart $12 / 19(63 \%)$, pancreas $10 / 19(53 \%)$, heart-lung $4 / 19(21 \%)$, and heart valve set $3 / 19(16 \%)$. Thirty two available organs were not retrieved because suitable recipients were not available (13), organ specific permission was not given by the next of kin (12), organ specific permission was not sought (4), retrieval teams were not available (2), or the reason was unknown (1).

\section{PROJECTED DONOR RATES IN NEW SOUTH WALES}

Projected donor rates for New South Wales using each of the methods described previously (see statistical methods) are listed in table VI. The realistic medically suitable potential donor rate in New South Wales calculated by the first method was $465 / 18665(2 \cdot 49 \%)$, and by the second method it was $311 / 18665(1 \cdot 67 \%)$. The calculation of the number of missed potential donors assumed that permission would be refused in $50 \%$ of cases and that resuscitation would have failed in $11 \cdot 6 \%$ (table VI)

\section{Discussion}

Our definition of a potential donor included all acutely brain damaged patients who were potentially or actually brain dead. Our study thus included patients who required ventilatory or haemodynamic support, or both, when imminently or apparently brain dead. Other studies about the potential for cadaveric organ retrieval have selected only potential donors who were actually brain dead. ${ }^{2} \rightarrow$ Therefore they would have excluded potential donors who with adequate resuscitation could have become actually brain dead. Our study, however, excluded those patients who remained in a stable vegetative state after withdrawal of support or in whom it was considered that resuscitation would have been solely for the purpose of organ retrieval. This latter exclusion could be eliminated if there was agreement that in patients whose prognosis was grave, usually from massive cerebral haemorrhage, it was ethically acceptable to resuscitate solely for organ retrieval. Feest et al recently showed that recruitment of such potential donors significantly increased the actual donor rate in a district hospital in England. ${ }^{10}$

Most previous studies of the potential for cadaveric organ retrieval have been based on intensive care units $^{2}$ or neurosurgical units ${ }^{6}$ and therefore may have omitted potential donors dying in other departments of the hospital, particularly primary and emergency care, coronary care, and neurology. Our audit has overcome this difficulty by including all deaths in hospital. Furthermore, studying five hospitals representing 15\% of all hospital deaths in New South Wales makes the sample one from which estimates of state wide potential can be derived.

The major obstacle to organ retrieval was the senior caring medical practitioner, who frustrated the organ retrieval process by withdrawing or by not instituting adequate resuscitation. Accurate identification of potential donors likely to be missed may help to overcome this obstacle (table V). In this regard, the important finding was that potential donors who did not present with brain death but became brain dead during hospitalisation were likely to be missed by medical practitioners. On the other hand, it should be noted that permission for organ retrieval had been sought from the vast majority of brain dead patients or their next of kin $(38 / 41,93 \%)$ and that a lack of awareness about the possibility of organ retrieval by medical staff occurred on only one occasion (table IV). It is to be hoped that in the intervention phase of this study (currently in progress) audit and follow up of all potential donors will help to raise awareness in the medical profession that missed potential donors can be converted to actual donors.

Failure of the next of kin to permit organ retrieval was the second most common cause of failing to convert realistic medically suitable potential donors to actual donors: it accounted for 17 out of $73(23 \%)$ of realistic medically suitable potential donors and 17 of $38(45 \%)$ of those asked for permission. Previous studies have reported that $30 \%$ of the next of kin refused permission. ${ }^{5}$ There is thus an urgent need to determine why relatives refused permission, given that a decision in favour of organ retrieval may help the relatives cope with bereavement. ${ }^{11}$ In this regard intense publicity about organ retrieval in the United Kingdom reduced the proportion of relatives refusing permission but failed to increase the actual donor rate (except for kidneys).

There are other ways of improving the donor rate: some debatably medically suitable potential donors may have been suitable despite having acute renal impairment. Available organs may be better used by reducing the non-retrieval rate. Finally, consideration should be given to resuscitating potential donors with hopeless prognoses for the purpose of diagnosing brain death and subsequent organ retrieval, provided permission for organ retrieval has been obtained.

\begin{tabular}{|c|c|c|c|c|c|c|}
\hline & \multicolumn{3}{|c|}{ Method I* } & \multicolumn{3}{|c|}{ Method II } \\
\hline & $\begin{array}{l}\text { No in New } \\
\text { South Wales }\end{array}$ & $\begin{array}{l}\text { No/million } \\
\text { population/year }\end{array}$ & $\begin{array}{l}\text { 95\% Confidence } \\
\text { interval }\end{array}$ & $\begin{array}{l}\text { No in New } \\
\text { South Wales }\end{array}$ & $\begin{array}{l}\text { No/million } \\
\text { population/year }\end{array}$ & $\begin{array}{l}\text { 95\% Confidence } \\
\text { interval }\end{array}$ \\
\hline Realistic medically suitable potential donors & 465 & 76 & 59 to 93 & 311 & 51 & 31 to 71 \\
\hline Missed potential donorsł & 91 & 15 & 7 to 23 & 57 & 9 & 4 to 15 \\
\hline Potential donors with permission refused & 112 & 18 & 10 to 27 & 81 & 13 & 5 to 22 \\
\hline Actual donors & 109 & 18 & 10 to 26 & 81 & 13 & $\|$ \\
\hline Actual plus missed potential donorsł & 200 & 33 & 21 to 44 & 138 & 23 & 12 to 33 \\
\hline $\begin{array}{l}\text { "Maximum" rate: actual plus missed potential donors } ₫ \\
\text { plus potential donors with permission refused } \uparrow\end{array}$ & 403 & 66 & 50 to 82 & 275 & 45 & 27 to 63 \\
\hline
\end{tabular}

*Assumes potential in New South Wales is that of the study hospitals.

†Assumes potential in New South Wales is that implied by the observed donor rate (13/million population/year).

$\ddagger$ Assuming $50 \%$ permission refusal rate and $11.6 \%$ failed resuscitation rate.

¥Assuming $50 \%$ permission refusal rate and $11.6 \%$ failed resuscitation rate.

Assuming $0 \%$ permission refusal rate and $11.6 \%$ failed resuscitation rate.

$95 \%$ Confidence interval not calculated for actual donors because this is the observed rate.

TMaximum donor rate could have been higher if patients over 70 years of age had been included in this study: 
The projected donor rates for New South Wales calculated by two different methods are contained in table VI. The differences in the rates are due to differences in the sizes of the potential donor poolthat is, the realistic medically suitable potential donor rate. If it is assumed that the realistic medically suitable potential donor rate for New South Wales is the same as that in the study hospitals then the actual donor rate would be as high as $18 /$ million population/year. On the other hand, the pool of potential donors implied by the actual donor rate (assuming the same conversion rate as observed in the study hospitals) is smaller than that projected in the first method $(51 / \mathrm{million}$ population/year $v 76 /$ million population/year). It is derived from an actual donor rate of 13/million population/year. The same explanation applies to differences in rates for missed potential donors and potential donors with permission refused for the two methods of projection. It is important to note, however, that even if the donor rate is $13 /$ million population/year there is opportunity to increase it by converting missed potential donors to actual donors (an increase of nine donors/million population/year) and by overcoming refusal of permission (an increase of 13 donors/million population/year). If both are overcome the projected rate would be $45 /$ million population/ year. Neither calculation of donor rates takes into account the possibility of potential donors created by interventional ventilation-that is, unrealistic potential donors in whom resuscitation would be solely for the purpose of organ retrieval.

It has been calculated that to satisfy the demand for cadaveric renal transplantation in New South Wales in 1990 and to catch up with the backlog over five years the supply rate needs to be increased $117 \%$; the actual donor rate needs to be increased by $15 /$ million population/year.' Assuming current community attitudes towards retrieval and our low projection of the potential for cadaveric retrieval, conversion of missed potential donors to actual donors would increase supply by about $70 \%(9 / 13$, table VI). If our high projection of the potential for cadaveric retrieval is assumed then the increase would be about $80 \%(15 / 18$, table VI).

In conclusion, this study has shown that there is significant unused potential for cadaveric organ retrieval in New South Wales. The two major obstacles are reluctance on the part of medical practitioners to resuscitate potential donors and refusal of permission by the next of kin. This study creates hope that by overcoming these two obstacles, cadaveric organ supply can be increased sufficiently to satisfy demand for all types of organ transplantation. It will be important to find out whether the first obstacle can be overcome by educational intervention among health care providers, and for this the second phase of this study is now in progress.

This work was supported by grants from the New South Wales Department of Health and Sandoz (Australia)

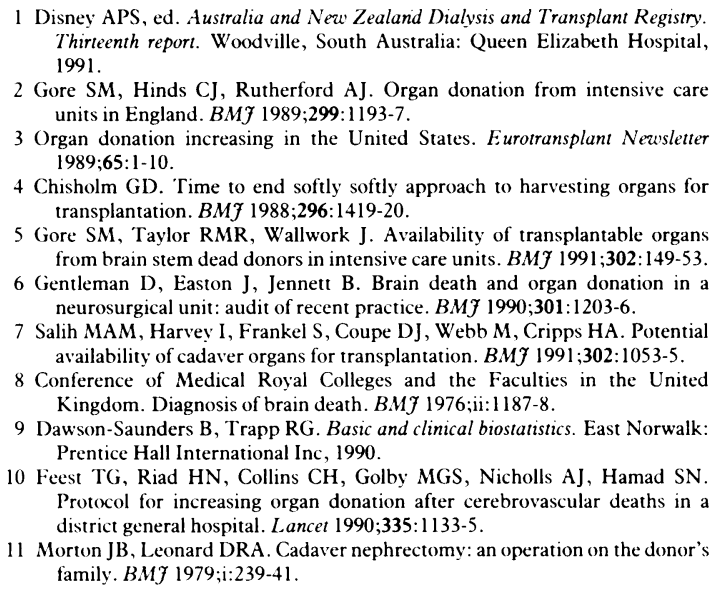

10 Feest TG, Riad HN, Collins CH, Golby MGS, Nicholls AJ, Hamad SN Protocol for increasing organ donation after cerebrovascular deaths in a district general hospital. Lancet 1990;335:1133-5.

11 Morton JB, Leonard DRA. Cadaver nephrectomy: an operation on the donor's family. BMF 1979;i:239-41.

Institute of Cancer

Research and Royal

Marsden Hospital, Sutton,

Surrey SM2 5PT

M Brada, senior lecturer and consultant in radiotherapy and oncology, neuro-oncology unit and academic unit of radiotherapy and oncology

D Ford, statistician, section of epidemiology

$S$ Ashley, computer analyst

J M Bliss, statistician, section of epidemiology

S Crowley, research assistant, neuro-oncology unit

M Mason, lecturer in radiotherapy and oncology, neuro-oncology unit B Rajan, visiting research fellow, neuro-oncology unit D Traish, research assistant, neuro-oncology unit

Correspondence to:

Dr Brada.

BMF 1992;304: 13+3-6

\title{
Risk of second brain tumour after conservative surgery and radiotherapy for pituitary adenoma
}

\author{
M Brada, D Ford, S Ashley, J M Bliss, S Crowley, M Mason, B Rajan, D Traish
}

\section{Abstract}

Objective-To assess the risk of second brain tumour in patients with pituitary adenoma treated with conservative surgery and external beam radiotherapy.

Design-Long term follow up of a cohort of patients with pituitary adenoma and comparison of tumour occurrence with population incidence rates.

Setting-The Royal Marsden Hospital.

Subjects -334 patients with pituitary adenoma treated with conservative surgery and radiotherapy (median dose $45 \mathrm{~Gy}$ ) and followed up for 3760 person years.

Main outcome measures-Second intracranial tumour and systemic malignancy.

Results-Five patients developed a second brain tumour: two had astrocytoma, two meningioma, and one meningeal sarcoma. The cumulative risk of developing a second brain tumour over the first $\mathbf{1 0}$ years after treatment was $1 \cdot 3 \%(95 \%$ confidence interval $0.4 \%$ to $3.9 \%)$ and over 20 years $1.9 \%(0.7 \%$ to $5.0 \%)$. The relative risk of a second brain tumour compared with the incidence in the normal population was 9.38 (3.05 to 21.89). There was no excess risk of any other type of second primary malignancy.

Conclusions - There is an increased risk of second intracranial tumour in patients with pituitary adenoma treated with surgery and radiotherapy. Although radiation is likely to be the most important factor contributing to the excess risk, further study is required in a cohort of similar patients not receiving radiation.

\section{Introduction}

Pituitary adenomas are successfully treated with a range of treatment modalities, which include surgery, radiotherapy, and medical treatment. ${ }^{1.7}$ Radiotherapy is principally employed to reduce the recurrence rate of incompletely excised non-secreting adenomas and in secreting pituitary tumours where hormonal control cannot be achieved with surgery and medical therapy. In these situations radiotherapy combined with limited surgery is successful in controlling pituitary adenoma, resulting in a $90 \% 10$ year progression free survival. ${ }^{134}$ Radiotherapy is relatively safe, with less than $1 \%$ 